Original Research Paper

\title{
Numerical Study of Post-Buckling of Clamped-Pinned Pipe Carrying Fluid Under Different Parameters
}

\author{
${ }^{1}$ Dahmane Mouloud, ${ }^{2 *}$ Samir Zahaf, ${ }^{3}$ Mawhoub Soubih, \\ ${ }^{4}$ Sid Ahmed Slimane, ${ }^{5}$ Benkhettab Mohamed and ${ }^{1}$ Djilali Boutchicha \\ ${ }^{1}$ LMA, Department of Mechanical Engineering, USTO-MB, BP 1055 El Menaour, Oran 31000, Algeria \\ ${ }^{2 *}$ Department of Technology, University of Djilali Bounaama-Khamis Meliana, Ain Defla-Algeria \\ ${ }^{3}$ Labortory of Mechanics and Energy, Chlef University Hassiba Benbouali, Chlef, Algeria \\ ${ }^{4}$ Department of Space Mechanical Research, Satellites Development Centre, Algerian Space Agency, \\ BP 4065, Ibn Rochd, USTO, Oran, POS 50 ILOT T12 Bir El Djir, Oran 31130, Algeria \\ ${ }^{5}$ Department of Mechanical Engineering, Mostaganem University-Abdelhamid Ibn Badis, Algeria
}

\author{
Article history \\ Received: 28-07-2020 \\ Revised: 03-09-2020 \\ Accepted: 21-09-2020 \\ Corresponding Author: \\ Samir Zahaf \\ Department of Technology, \\ University of Djilali \\ Bounaama-Khamis Meliana, \\ Ain Defla-Algeria \\ Email: samir.zahaf@univ-dbkm.dz \\ zahafsamir1983@gmail.com
}

\begin{abstract}
This research aims to calculate the first three natural frequencies and critical velocity of a fluid-conveying pipe are obtained with numerical approach with standard finite element method and this by discretizing the structure wall and internal flow, starting from beam type with two degrees of freedom per node. The determination is done to the vibrational equation from the fluid-structure coupling using Lagrange energy principle. Parameters frequencies are calculated by using a program developed on MATLAB. The advantage of MATLAB language by using standard functions is to present the first Eigen-modes of the system aspect interaction fluid-structure for different physic and geometric parameters in complex planes. The results are converged and compared with those predicted by semi-analytic method. Numerical results show the effect of mass ratio, length and elastic foundation on stability region and static instability and static instability range.
\end{abstract}

Keywords: Fluid-Conveying Pipe, Natural Frequency, Velocity, Instability, Elastic Foundation, FEM, MATLAB

\section{Introduction}

The investigation of free vibration and the stability of pipes carrying fluid have attracted the attention of many researchers in the last few periods. The results were used in several fields, such as pipelines (Wiggert and Tijsseling, 2001), engineering industries (Antaki, 2003), hydraulic (Al-Maliky, 2013), nanotube (Ghayesh et al., 2018), thermal power plants (Weaver et al., 2000), heating exchangers as nuclear production (Sastry, 1982), etc. Study of this subject is much ramified. Païdoussis and Besancon (1981; Païdoussis, 1981; Païdoussis and Curling, 1985) is the most famous researcher on the topic of mating and thanks to his research, the linear and non-linear equation of the pipes motion was obtained under the influence of many factors (Païdoussis and Moon, 1988; Païdoussis et al., 2007; Païdoussis and Li, 1993). Later on, he published two books (Païdoussis, 2014 ; 2016) on fluid-structure interactions and the stability of pipes conveying fluid with different parameters. His studies have become a basic reference for all contemporary research. Doaré after him in references (Doaré and de Langre, 2002a; 2002b), he touched better on the issue of static instability and dynamic instability. In his studies, he presented analytical models by calculating the critical velocities of fluid. Then, studies continued on this subject and it touched the industrial field. Doaré and al. studied instability of fluid conveying pipes on Winkler elastic foundation. The focus in their paper was on instability of infinitely long pipes carrying fluid, by using wave propagation approach, wherein results are interpreted in terms of static instability neutrality as analytic criteria for boundary condition: Pinned-pinned and clampedclamped and dynamic neutrality for clamped-free pipe (Doaré and de Langre, 2006). Instabilities cause damage and fatigue to the system, so it must be studied with various physical and geometrical factors. Maalawi and Ziada (2002) studies has presented a mathematical model for determining the speed velocity of a pinned-pinned pipe composed of uniform modules, design parameters include the wall thickness and with the length. Mohsen and al. studied in the experimental approach based on estimating the critical velocities from the measurement 
of several fundamental natural frequencies, where utilizing the boundary condition: Pinned-pinned, clamped-pinned and clamped-clamped. In this approach low flow-rate pumps and simple fluid circuit can be used. The results were used for analysis the buckling (static instability) (Ismail et al., 2011). Recently, another work by the experimental approach for estimating buckling critical velocities from measuring several natural frequencies at relatively small flow rates is presented (Jweeg and Ntayeesh, 2016). The results show good agreement between the estimated and theoretical critical velocities in case of pinned-pinned and clampedpinned pipes. However for clamped-clamped pipes the accurate estimation requires higher flow rates. The method can serve using a relatively low pump discharge and simple fluid circuit instead of high discharge pumps which demand complication in the fluid circuits.

As presented in the research and results presented, this work mainly depends on the so-called Finite Element Method (FEM), where the critical velocity of flow is calculated according to the disappearance of the first natural frequency which is followed by the appearance of the first instability pattern (buckling), passing to dynamic instability (flutter), taking into account the boundary condition and effect of different parameters and on it, the first natural frequencies and critical velocities of the system are calculated using a program developed on MATLAB. This allows us to study static instability of buckling and discover its most important characteristics.

\section{Differential Equation of Motion}

The problem to be considered is the vibration analysis of a fluid conveying pipe system on an elastic foundation Winkler-model. The derivation of the equation is based on Bernoulli- Euler elementary beam theory. The physical model of system is shown in Fig. 1. Figure 2 shows forces on fluid element, and forces and moment of pipe element (Païdoussis, 2014; 2016).

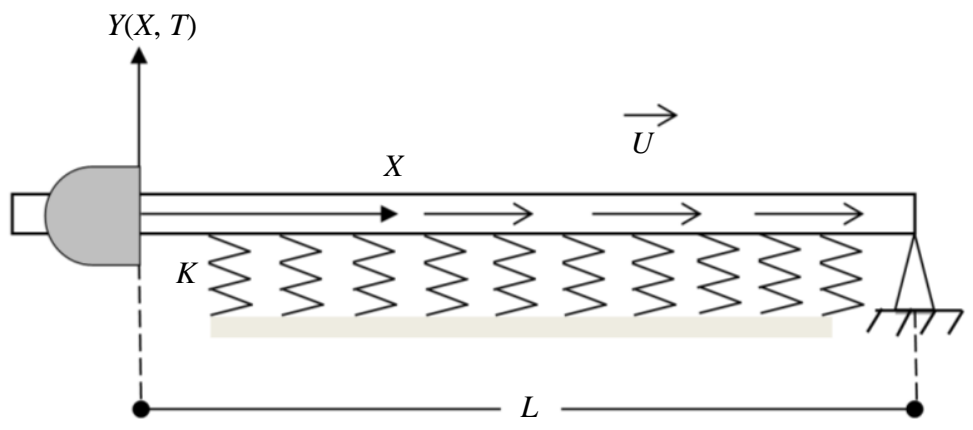

Fig. 1: Representation of the clamped-pinned pipe conveying fluid resting on elastic foundation

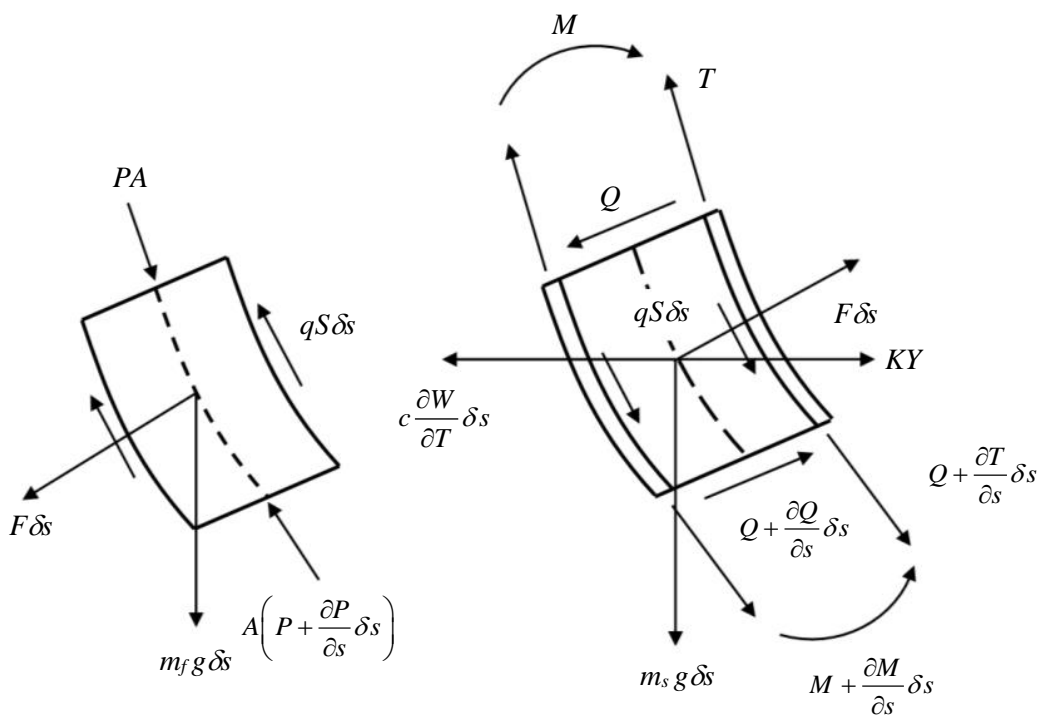

(a)

(b)

Fig. 2: (a) forces on fluid element; (b) forces and moments on pipe element $\delta$ s 
The equation of motion for pipe carrying fluid on a Winkler elastic foundation is given as (Païdoussis, 2014):

$$
\begin{aligned}
& E I \frac{\partial^{4} Y}{\partial X^{4}}+m_{f} U^{2} \frac{\partial^{2} Y}{\partial X^{2}}+2 m_{f} U \frac{\partial^{2} Y}{\partial X \partial T} \\
& +\left(m_{s}+m_{f}\right) \frac{\partial^{2} Y}{\partial T^{2}}+K Y=0
\end{aligned}
$$

Where, the pipe is long and straight $L$ conveying an incompressible fluid with steady speed $U$; the motions are small $\delta s$. The elastic foundation Winkler-model is $K Y, m_{s}$ and $m_{f}$ the masses per unit length of the pipe and the fluid, respectively. The Boundary conditions are,

$$
\left.Y\right|_{X=0}=\left.\frac{\partial Y}{\partial X}\right|_{X=0}=\left.Y\right|_{X=L}=\left.\frac{\partial^{2} Y}{\partial X^{2}}\right|_{X=0}=0
$$

Where, the non-dimensional parameters (Païdoussis, 2014; 2016), are:

$$
\begin{aligned}
& x=X / L, y=Y / L, t=\left(E I /\left(m_{f}+m_{s}\right)^{1 / 2}\right) T / L^{2}, \\
& \beta=m_{f} /\left(m_{f}+m_{s}\right), \\
& u=U L\left(m_{f} / E I\right)^{1 / 2}, k=K L^{2} / E I
\end{aligned}
$$

Where, the potential (deformation) energy and the kinetic energy of the solid element expressed by:

$$
V_{1}=\frac{1}{2} \int_{0}^{L} E I\left(\frac{d^{2} W}{d X^{2}}\right)^{2} d X
$$

$$
E_{C s}=\frac{1}{2} \int_{0}^{L} m_{s} \frac{d^{2} W}{d T^{2}} d X
$$

The kinetic energy of the fluid element can be expressed:

$$
E_{C f}=\frac{1}{2} \int m_{f}\left(U \frac{d W}{d X}+\frac{d W}{d T}\right)^{2} d X
$$

The potential energy over the length of elastic foundation can be expressed:

$$
V_{2}=\frac{1}{2} \int_{0}^{L} K W^{2} d X
$$

The equation of element deflection for straight two dimensional beam elements could have the form (Rao, 2011):

$$
W(X, T)=\sum_{i=1}^{N} N_{i}(X) W_{i}(T)
$$

Where, $\left[N_{i}\right]$ represent the shape function and $W_{i}(T)$ is the function which represents the shape of the displacements and rotations at nodes, see Fig. 3. The Fig. 4 shows the dimensionless coordinates.

Therefore, Equation (7) becomes:

$$
\begin{aligned}
& W(X, T)=N_{1}(X) W_{1}(T)+N_{2}(X) \theta_{1}(T) \\
& +N_{3}(X) W_{2}(T)+N_{4}(X) \theta_{2}(T)
\end{aligned}
$$

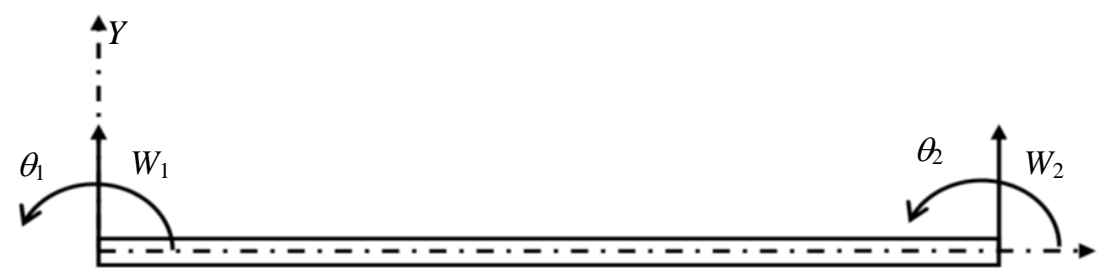

$X$

Fig. 3: Beam element nodal displacements; Where, $W_{1}, \theta_{1}, W_{2}$ and $\theta_{2}$ : Are the displacements and rotations at the nodes

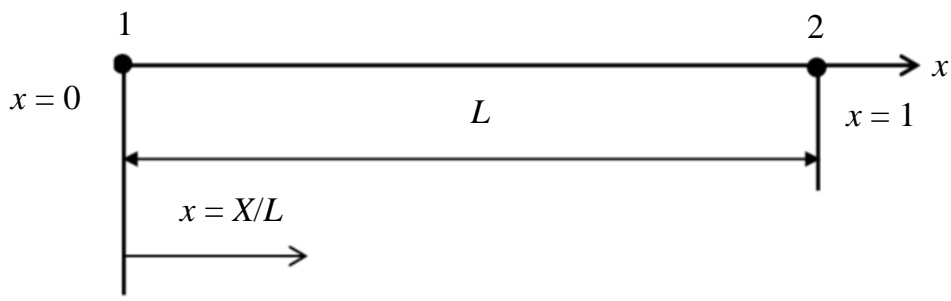

Fig. 4: Reference element 
Forming shape functions:

$$
\left\{\begin{array}{l}
N_{1}=1-3 x^{2}+2 x^{3} \\
N_{2}=L\left(x-2 x^{2}+3 x^{3}\right) \\
N_{3}=3 x^{2}-2 x^{3} \\
N_{4}=L x^{2}(x-1)
\end{array}\right.
$$

where, $0 \leq x \leq 1$.

Lagrange's principle:

$$
\frac{d}{d T}\left(\frac{\partial E_{C}}{\partial \dot{q}_{i}}\right)-\frac{\partial E_{C}}{\partial \dot{q}_{i}}+\frac{\partial V}{\partial q_{i}}=0
$$

The standard equation of motion in the finite element form is:

$$
[M]\{\ddot{q}\}+[C]\{\dot{q}\}+([K])\{q\}=0
$$

Where:

$$
\begin{aligned}
{[M]=\left[M_{s}\right]+\left[M_{f}\right]=} & \text { Elementary mass matrix of the system } \\
= & \text { Elementary damping matrix of the } \\
& \text { system } \\
{[K]=\left[K_{s}\right]-\left[K_{f}\right]=} & \begin{array}{l}
\text { Elementary stiffness matrix of the } \\
\text { system }
\end{array}
\end{aligned}
$$

Considering the displacement vector as:

$$
\{Q\}=\{E\} \cdot \exp (\lambda t)
$$

The governing equation of the system for fluid-structure coupling can be transformed into its state-space:

$$
\left\{\left[\begin{array}{cc}
0 & I \\
-M^{-1} K & -M^{-1} C
\end{array}\right]-\lambda\left[\begin{array}{cc}
I & 0 \\
0 & I
\end{array}\right]\right\}\left[\begin{array}{c}
\lambda\{E\} \\
\{E\}
\end{array}\right]=\left[\begin{array}{l}
0 \\
0
\end{array}\right]
$$

where, $I$ is the identity matrix,

Complex conjugate Eigen-values, $\lambda^{m}=R e^{m}+j \omega^{m}$.

The stability and static instability of the system under consideration is determined by the sign of real part and the natural frequencies values (the imaginary part) of the complex Eigen-value.

\section{Results and Discussion}

In studying and analyzing the concept of instability, the fundamental natural frequency of a pipe decreases with increasing fluid velocity. There are certain cases where a decrease in this natural frequency can be very important and with large fluid velocities, the pipe may become unstable. Results will be discussed for various values of $\beta$, length $L$, elastic foundation $k$ (Winkler type) and the instability parameters for clamped-pinned pipe. The elastic modulus of pipe is $(E=207 \mathrm{GPa})$, pipe length is $(L=1 \div 2 \mathrm{~m})$, fluid density is $\left(m_{f}=1000\right.$ $\left.\mathrm{kg} / \mathrm{m}^{3}\right)$, pipe density is $\left(m_{s}=7850 \mathrm{~kg} / \mathrm{m}^{3}\right)$, pipe thickness for $(\beta=0.1 \div 0.9)$ and the outer diameter of the pipe is $(0.03 \mathrm{~m})$.

Boundary conditions with clamped-pinned ends give the system more rigidity and stability than pinned-pinned ends and less than the clamped-clamped ends. So, the raise of the flow velocity is needed to reach the desired goal, which is the critical velocity in both modes. The cases can be divided into three; according to the parameters effect masse ratio $\beta$, length $L$ and Winkler elastic foundation.

The validation of our program was made by doing a convergence study. Convergence was performed for two velocities, Fig. 5 shows the first three proper modes according to $U=175 \mathrm{~m} / \mathrm{s}$. There is very fast convergence for the first two modes according to the number of elements. Convergence is obtained for the third mode with 13 elements. The program has been validated with reference (Ni et al., 2011) by calculating the first three dimensionless frequencies as a function of the fluid velocity for clamped-pinned pipe with internal fluid and $\beta=0.5$. The Table 1 shows that the dimensionless results obtained numerically are similar to those obtained by the semi-analytical approach so-called DTM. The biggest change in the range of $6 \%$ is very acceptable. It is preferable to use a dimensioning to see the effect of flow velocity and mass ration on natural frequencies developments. So, the Fig. 6 shows the variation of the three first natural frequencies as function of fluid velocity with three mass rations, (a) $\beta=0.1$, (b) $\beta=0.3$ and (c) $\beta=0.5$, respectively. For $U \equiv 0$ (fluid at rest), the biggest variation on frequencies is $37 \%$. Based on the first case, where $\beta=0.1$, for $U \equiv U_{c r}$, that is the first critical velocity (velocity of static instability) $U=$ $869.53 \mathrm{~m} / \mathrm{s}$, decrease by $77 \%$ in the third case $(\beta=0.5)$, where the critical velocity reaches $199.50 \mathrm{~m} / \mathrm{s}$, while the critical speed is equal $256,05 \mathrm{~m} / \mathrm{s}$ for $\beta=0.3$. The biggest variation of instability static range is $46 \%$. So, an increase in the value of $\beta$ leads to a decrease in the stability region, critical velocities, as well as the instability range. The effect of all this analysis is that damping in this type of behavior is positive which leads with the passage of time to gradually reduce the rigidity of the system down to flutter. Other than the dimensional results, dimensionless results obtained do not show these changes for different mass ratios, Fig. 7. The second discourse of this paper deals with the study of the effect of length on the natural frequencies as a function of the 
fluid velocity for three different lengths $(L=1, L=1.5$, $L=2$ ), with mass ratios $\beta=0.3$ Fig. 8 . The variations show that length has significant effect on the rigidity which lowers the frequencies of the system according to the flow velocity and consequently quickly reaches the first critical velocity of buckling. The biggest variation is equal to $44 \%$, where the critical velocity of static instability drops from $1.44 \pi$ to $1.19 \pi(L=1.5)$ and to 1.08 for $L=2$, while the biggest variation on natural frequencies do not exceed value of $16.50 \%$. The change in the level of instability range is evident, increasing with the increase in length, where the changes reach
$38.93 \%$. The last case is devoted to the study of the first natural frequencies of a clamped-pinned pipe carrying fluid which rests on an elastic foundation such as Winkler-type. The effect of the elastic is stabilizing for the system, as show in the Fig. 9. Four different values of k-Winkler type were used. The stability of the system increases with increasing $\mathrm{k}$, with the critical velocity corresponding to static instability, while decreasing the instability range as shown in the Fig. 9 depending on, as the biggest change is found over $58 \%$. The critical velocity of static instability is $2.67 \pi$ for $k=10^{3}$, with an increase of $45.31 \%$.

\section{Mass Ratio Effect}

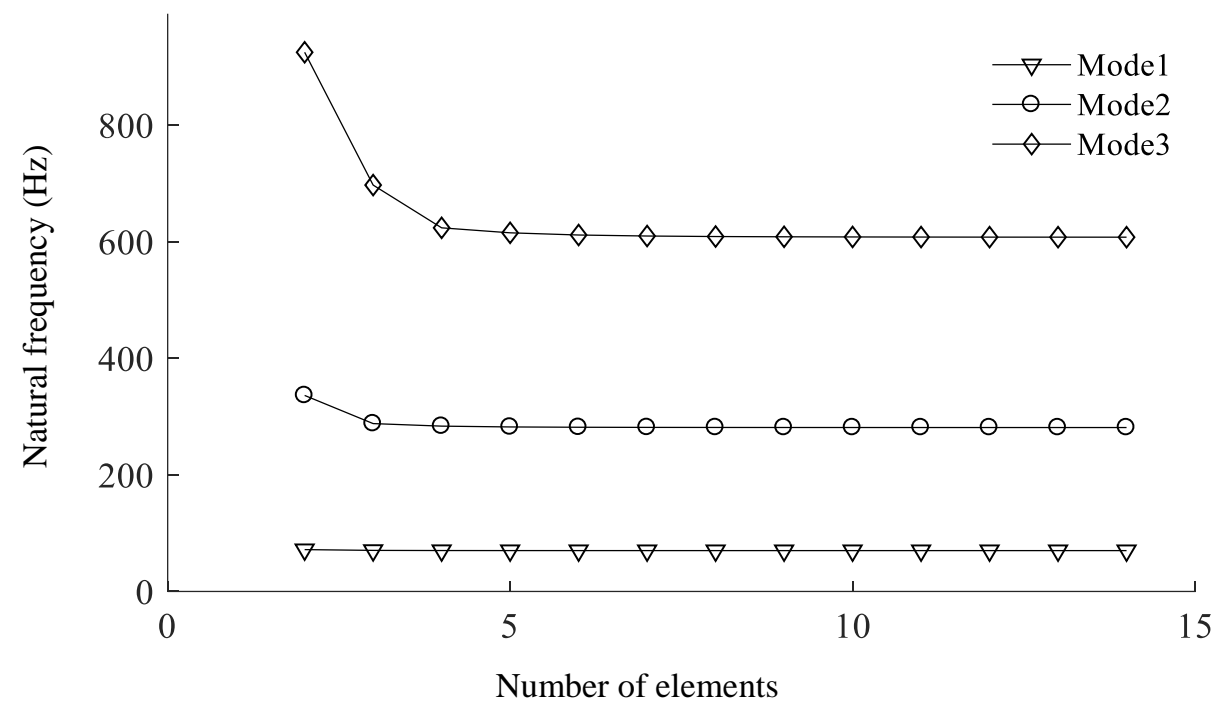

Fig. 5: Convergence of the first three natural frequencies of clamped-pinned pipe, $U=150 \mathrm{~m} / \mathrm{s}, \beta=0.5$



(a) 


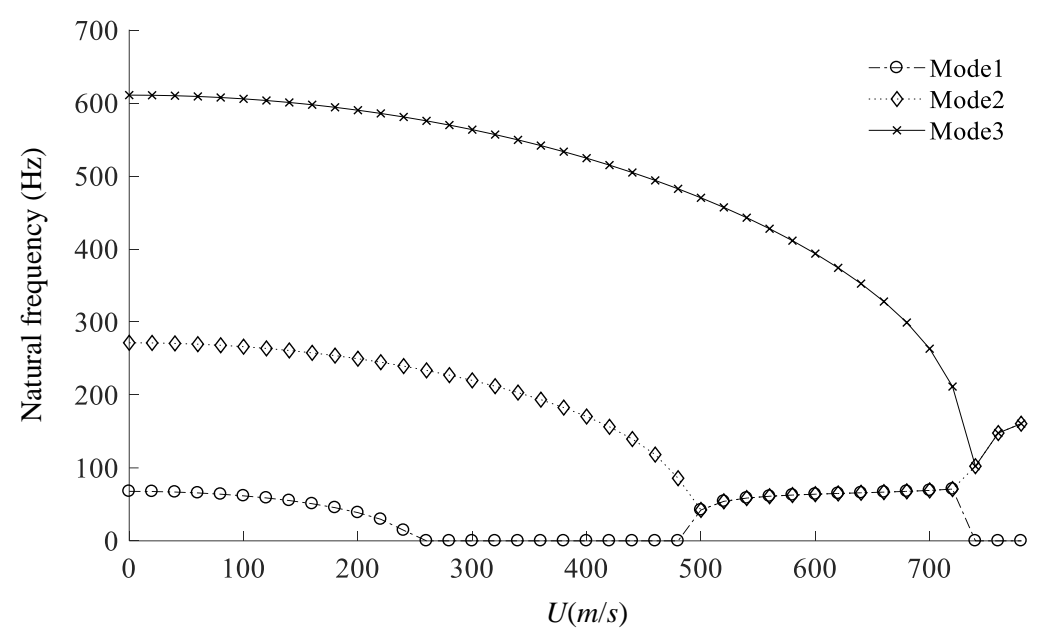

(b)

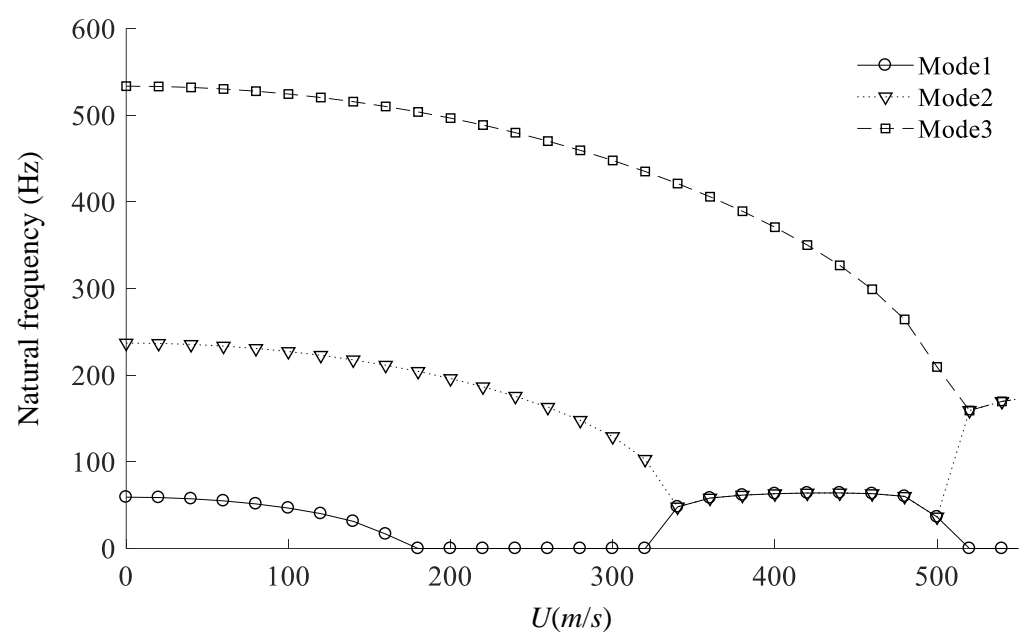

(c)

Fig. 6: Three proper modes on fluid velocity function of clamped-pinned pipe conveying fluid with different mass ratio, (a) $\beta=0.1$, (b) $\beta=0.3$, (c) $\beta=0.5$

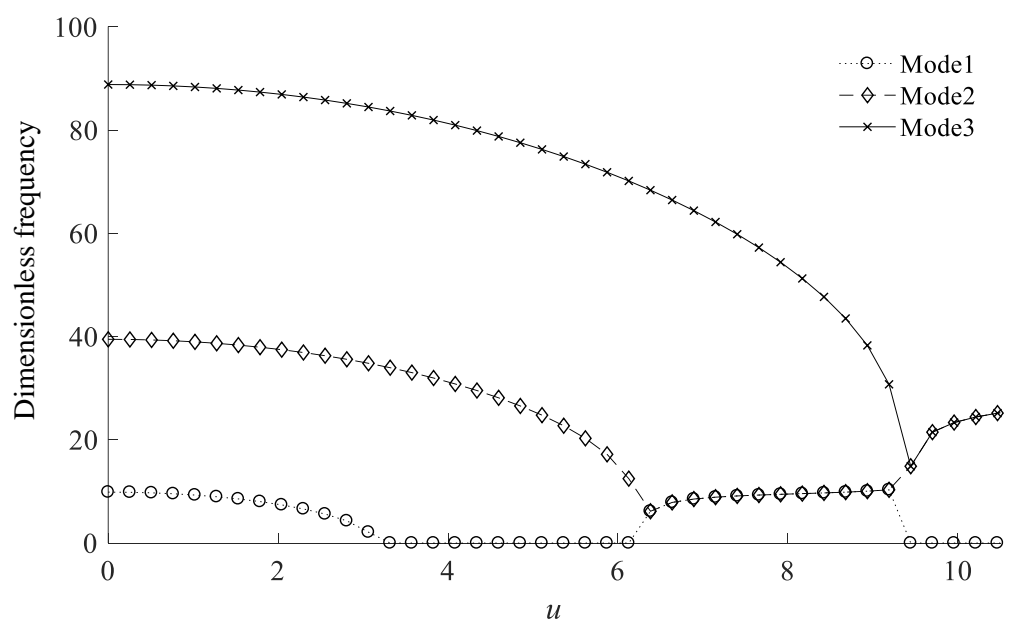

(a) 


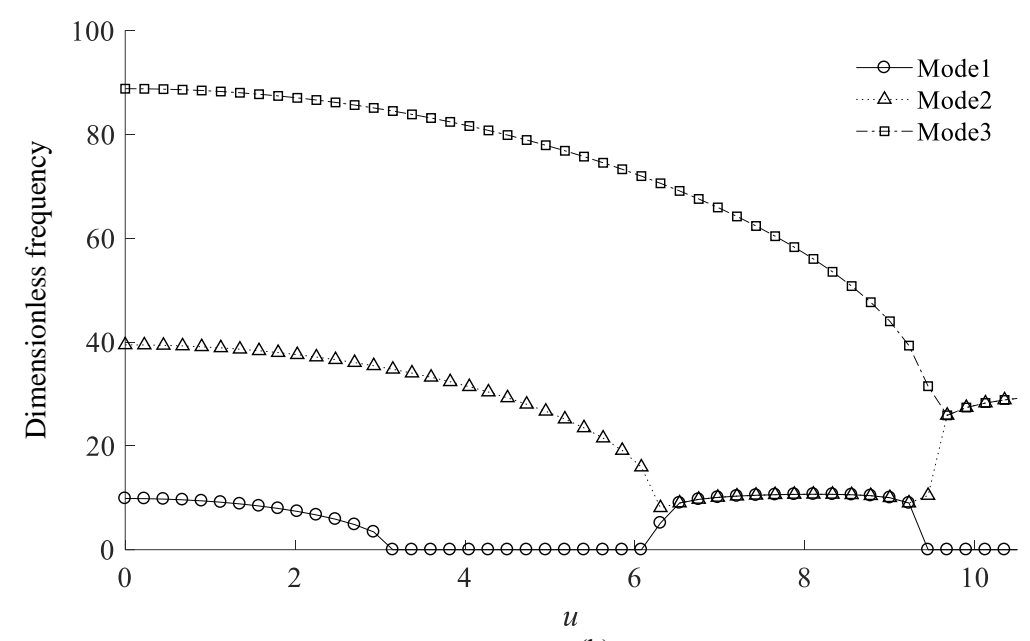

(b)

Fig. 7: Three proper modes on fluid velocity function of Clamped-pinned pipe conveying fluid, (a) $\beta=0.3$, (b) $\beta=0.5$

\section{Length Effect}
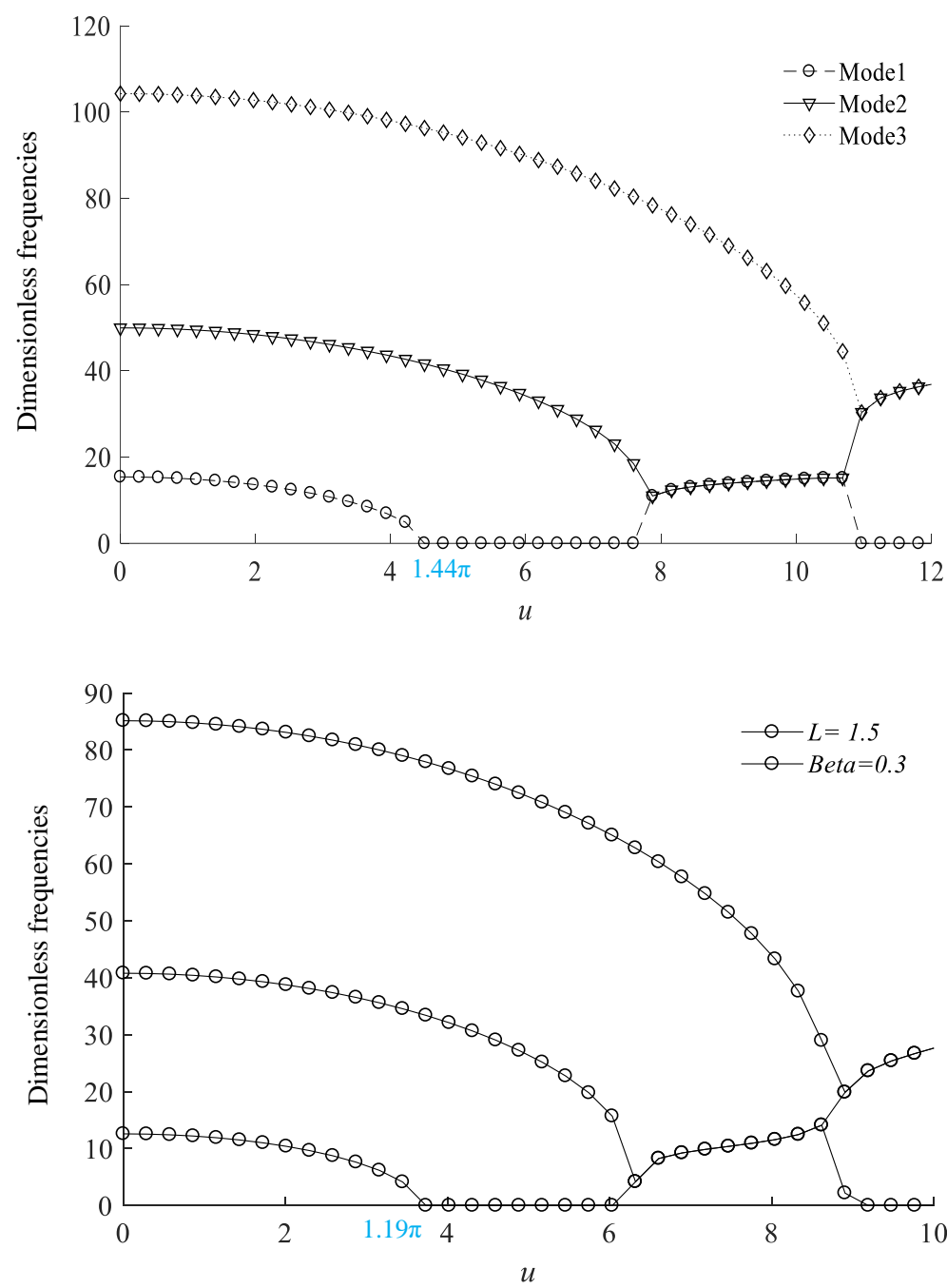


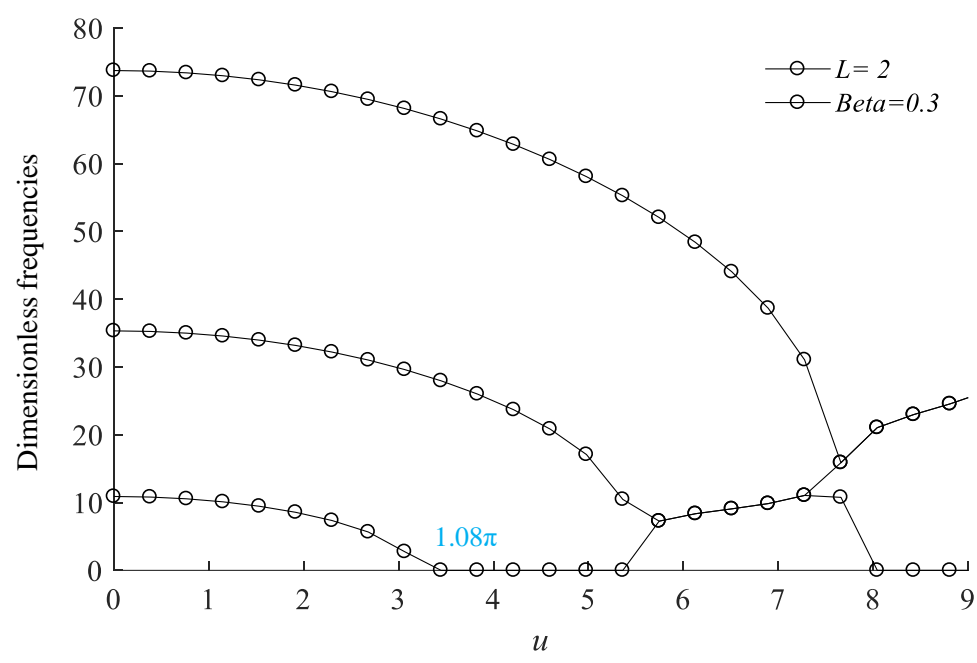

Fig. 8: Effect of length on the natural frequency of the pipe at different fluid velocities

\section{Elastic Foundation Effect}


Fig. 9: Effect of foundation stiffness on the natural frequency of the clamped-pinned pipe at different fluid velocities, $\beta=0.3$ 
Table 1: The first natural frequency of a clamped-pinned fluidconveying pipe for various values of $u$ and $\beta=0.1$

\begin{tabular}{llll}
\hline & $\beta=0.1$ & & \\
& -------------------- & \\
$u$ & $\Omega_{1}$ DTM & $\Omega_{1}$ FEM & Variation \\
\hline 0.0 & 15.4183 & 15.4181 & 0.000 \\
0.1 & 15.4131 & 15.4106 & 0.016 \\
0.5 & 15.4001 & 15.3214 & 0.511 \\
1.0 & 14.9797 & 15.0276 & 0.319 \\
2.0 & 13.6124 & 13.7932 & 1.328 \\
3.0 & 11.1054 & 11.4542 & 3.140 \\
4.0 & 6.6146 & 7.0170 & 6.083 \\
4.499 & 0.0000 & 0.0000 & 0.000 \\
\hline
\end{tabular}

\section{Conclusion}

The free vibration of pipe transporting a fluid is treated, for boundary conditions: Clamped-pinned ends. The pipe structure and internal flow were modeled by EulerBernoulli beam. The numerical aspect with the finite method gives solutions in a complex plane by determining the proper modes of our system; the numerical results are finally combined with the semi-analytic results DTM. Several examples have been treated for the study of the influence of different geometric and physic parameters on the system instability. The first observation that can be made is that the natural frequencies of the system weight the velocity of the flow. The instability appears when the flow velocity exceeds a threshold called critical velocity of static instability, when the first frequency is equal to zero (the first proper mode disappears). It had noticed that increasing $\beta$ slightly decreases the rigidity of the system (by loss of rigidity) and the system consequently decreases their natural frequencies. The result showed a large variation in the values of stability region and instability with the increase in the mass ratio. It had noticed that increasing length L slightly decreases the stability region and critical velocity of instability and consequently leads to an increase in the instability range. The typical Winker elastic foundation increases the rigidity of the system and consequently the natural frequencies and the critical velocities. What distinguishes most of this research from others is its discussion of the axis of instability and what it means in this field that is why some analysis and calculation were done in the presented research, hoping to continue with other work in the same field.

\section{Acknowledgment}

Thanks to group members who contribute in this research from the first one to the last.

\section{Author's Contributions}

Dahmane Mouloud, Samir Zahaf and Benkhettab Mohamed: The authors of the idea and the research conduced the theoretical study.
Mawhoub Soubih and Sid Ahmed Slimane: Extracted elementary matrix using the finit element method.

Djilali Boutchicha: Undertook programming using the Matlab code.

\section{Ethics}

This article is original and contains unpublished material. The corresponding author confirms that all of the other authors have read and approved the manuscript and no ethical issues involved.

\section{References}

Al-Maliky, R. F. (2013). Force convection of laminar liquid flow inside pipe exerted to non-uniform heat flux. Int J Therm Technol, 3(3), 113-9.

Antaki, G. A. (2003). Piping and pipeline engineering: Design, construction, maintenance, integrity and repair. CRC Press.

Doaré, O., \& de Langre, E. (2002a). Local and global instability of fluid-conveying pipes on elastic foundations. Journal of fluids and structures, 16(1), $1-14$.

Doaré, O., \& de Langre, E. (2002b). The flow-induced instability of long hanging pipes. European Journal of Mechanics-A/Solids, 21(5), 857-867.

Doaré, O., \& de Langre, E. (2006). The role of boundary conditions in the instability of one-dimensional systems. European Journal of Mechanics-B/Fluids, 25(6), 948-959.

Ghayesh, M. H., Farokhi, H., \& Farajpour, A. (2018). Chaotic oscillations of viscoelastic microtubes conveying pulsatile fluid. Microfluidics and Nanofluidics, 22(7), 72.

Ismail, M. R., Yousif, A. E., \& Jweeg, M. J. (2011). Experimental estimation of critical buckling velocities for conservative pipes conveying fluid. Al-Khwarizmi Engineering Journal, 7(4), 17-26.

Jweeg, M. J., \& Ntayeesh, T. J. (2016). Determination of critical buckling velocities of pipes conveying fluid rested on different supports conditions. International Journal of Computer Applications, 134(10), 34-42.

Maalawi, K. Y., \& Ziada, M. A. (2002). On the static instability of flexible pipes conveying fluid. Journal of fluids and structures, 16(5), 685-690.

Ni, Q., Zhang, Z. L., \& Wang, L. (2011). Application of the differential transformation method to vibration analysis of pipes conveying fluid. Applied Mathematics and Computation, 217(16), 7028-7038.

Païdoussis, M. P. (1981). Fluidelastic vibration of cylinder arrays in axial and cross flow: state of the art. Journal of Sound and Vibration, 76(3), 329-360.

Païdoussis, M. P. (2014). Fluid-structure interactions slender structures and axial flow. Academic Press, London. 
Païdoussis, M. P. (2016). Fluid-structure interactions slender structures and axial flow. Academic Press, Elsevier.

Païdoussis, M. P., \& Besancon, P. (1981). Dynamics of arrays of cylinders with internal and external axial flow. Journal of Sound and Vibration, 76(3), 361-379.

Païdoussis, M. P., \& Curling, L. R. (1985). An analytical model for vibration of clusters of flexible cylinders in turbulent axial flow. Journal of Sound and Vibration, 98(4), 493-517.

Païdoussis, M. P., \& Li, G. X. (1993). Pipes conveying fluid: a model dynamical problem. Journal of fluids and Structures, 7(2), 137-204.

Païdoussis, M. P., \& Moon, F. C. (1988). Nonlinear and chaotic fluidelastic vibrations of a flexible pipe conveying fluid. Journal of Fluids and Structures, 2(6), 567-591.
Païdoussis, M. P., Semler, C., Wadham-Gagnon, M., \& Saaid, S. (2007). Dynamics of cantilevered pipes conveying fluid. Part 2: dynamics of the system with intermediate spring support. Journal of Fluids and Structures, 23(4), 569-587.

Rao, S. S. (2011). The finite element method in engineering. Elsevier Science \& Technology Books.

Sastry, H. S. N. (1982). Influence of ship vibration on heat exchangers. Def Sci J. 32(1), 35-40

Weaver, D. S., Ziada, S., Au-Yang, M. K., Chen, S. S., Païdoussis, M. P., \& Pettigrew, M. J. (2000). Flowinduced vibrations in power and process plant components-progress and prospects. J. Pressure Vessel Technol., 122(3), 339-348.

Wiggert, D. C., \& Tijsseling, A. S. (2001). Fluid transients and fluid-structure interaction in flexible liquid-filled piping. Appl. Mech. Rev., 54(5), 455-481. 